American Journal of Pharmaceutical Education 2020; 84 (10) Article 7764.

\title{
RESEARCH
}

\section{Integrating Health Literacy and Cultural Competency Concepts Across the Doctor of Pharmacy Curriculum}

\author{
Aleda M. H. Chen, PharmD, PhD, Stephanie M. Cailor, PharmD, Emily Wicker, BSPS, \\ Nicole G. Harper, BSPS, Thad T. Franz, PharmD, Brenda Pahl, PharmD \\ Cedarville University, School of Pharmacy, Cedarville, Ohio \\ Submitted June 10, 2019; accepted May 16, 2020; published October 2020.
}

\begin{abstract}
Objective. To determine the longitudinal impact of integrating health literacy and cultural competency content throughout the professional pharmacy curriculum and the impact of additional changes made to the curriculum based on the results of a longitudinal analysis.

Methods. Health literacy and cultural competency concepts were integrated throughout a four-year professional pharmacy curriculum. A cohort of students were assessed using health literacy and cultural competency survey instruments at baseline, the end of the fall semester of the first professional (P1) year, and the end of each subsequent academic year. From the four-year assessment, a need for additional reinforcement in the spring P1 semester was identified, so a health literacy activity was incorporated into an introductory pharmacy practice experience (IPPE) for two cohorts of students. The outcomes were compared to those of a single cohort of students who had completed their P1 year prior to integration of the additional content. A health literacy survey instrument was given at the beginning and after completion of the semester to assess change. Preceptors also completed a brief survey.

Results. Curricular integration improved health literacy and cultural competency attitudes and selfperceived ability in P1 students, as assessed by the instruments. However, declines in students' health literacy and cultural competency were identified when the students were retested in the spring semester. After implementing the health literacy IPPE activity, the health literacy scores of P1 students in the two subsequent years improved. Preceptors also gave positive feedback on the utility of this activity.

Conclusion. Integrating health literacy and cultural competency content throughout the curriculum resulted in improvement in students' scores in these areas from the first to the fourth professional year, but when there were no integrated activities, scores dropped. Implementing additional activities improved student-perceived HL skills. Thus, it may be important to ensure there is inclusion of content in each semester of the curriculum to maximize effects.
\end{abstract}

Keywords: pharmacy, health literacy, cultural competency, integration, curriculum

\section{INTRODUCTION}

In the United States, health information is often written at the highest reading levels, despite that only $12 \%$ of US adults scoring in the highest proficiency levels and only $9 \%$ scoring in the highest numeracy levels. ${ }^{1}$ Health literacy is defined as the ability to obtain and use health information for decision-making. ${ }^{2}$ Patients with low health literacy face greater health disparities and significantly higher health care costs than those with adequate literacy, costing the US health care system an estimated \$106-\$238 billion annually. ${ }^{3}$ Also, low health literacy rates are often correlated with decreases in medication

Corresponding Author: Aleda M. H. Chen, Cedarville University, School of Pharmacy, 251 N. Main St., Cedarville, OH 45314. Tel: 937-766-7454. E-mail:

amchen@cedarville.edu adherence rates. ${ }^{4}$ Pharmacists are in a unique position to address this issue, as they function as a mediator between the prescriber and the patient, educating patients about their medications to ensure they understand how to use them properly. By using clear communication principles, pharmacists can navigate health literacy barriers effectively. ${ }^{5}$

Similarly, pharmacists must demonstrate cultural and linguistic competence when working with patients of diverse backgrounds. Cultural competency is the ability of the pharmacist to work effectively with all patients in a manner which values and respects differences as well as similarities. ${ }^{6}$ Culture impacts health care decisions and can be related to health disparities. Thus, it is essential for a practitioner to be sensitive to and inclusive of cultural beliefs to achieve the best outcomes for the patient. ${ }^{6-8}$ 


\section{American Journal of Pharmaceutical Education 2020; 84 (10) Article 7764.}

Integration of health literacy and cultural competency into the pharmacy didactic and experiential curriculum to ensure graduates are practice ready has been emphasized by the Accreditation Council for Pharmacy Education (ACPE) in Standards 2016, the American Association of Colleges of Pharmacy (AACP) Center for Pharmacy Advancement (CAPE) in the 2013 Domains, and the American College of Clinical Pharmacy (ACCP) White Papers on Cultural Competency. ${ }^{6-11}$ These skills also are incorporated into the Joint Commission of Pharmacy Practitioners' (JCPP) Pharmacists' Patient Care Process, explicitly in the Collect and Assess steps and implicitly in each step. ${ }^{12}$ Health literacy and cultural competency courses, electives, activities, experiential education, and presentations have been effectively incorporated into the curricula of pharmacy schools to address this problem; however, most have limited inclusion throughout the curriculum and instead focus on a single activity, course, experience, or elective. ${ }^{14-25}$

Gaps in pharmacist and student pharmacist preparedness in the areas of health literacy and cultural competency remain despite enhanced curricular efforts. ${ }^{8,13}$ For example, in a scoping review of over 100 articles that were analyzed for key themes, pharmacists were found to often have negative assumptions about certain patient groups and constrained interactions because of a lack of knowledge. The authors identified "problematic patterns important to equitable care, including deficits in what pharmacists know about the needs and preferences of certain marginalized populations, negative perceptions of these populations and their related care, and gaps in the accessibility and adequacy of services."13 Clearly, pharmacy schools need to continue to assess the longitudinal effectiveness of interventions and should examine a comprehensive, integrated approach to these concepts in the didactic and experiential curriculum to build skills needed for equitable care. This two-part study aimed to close a gap in knowledge by determining the longitudinal impact of the comprehensive integration of health literacy and cultural competency components over the span of a pharmacy professional program on students' health literacy and cultural competency and the impact of changes made to the curriculum following the longitudinal assessment.

\section{METHODS}

Cedarville University's Institutional Review Board approved each component of this two-part study. Participation in the surveys and data collection were voluntary, but participation in the activities was required. In brief, the first part of the study was a four-year assessment of integrated health literacy and cultural competency components throughout the professional pharmacy program. Based on the data obtained from the first part, curricular elements related to these concepts were added to address areas of concern identified by the assessment.

The Cedarville University School of Pharmacy is in a small, midwestern town that is within a one-hour drive of several larger, more culturally diverse cities where student experiences are provided. These cities range in population from approximately 59,000 to 890,000 . According to population data for these urban areas, approximately $60 \%$ of the population is white; $29 \%$, black or African American; $4.2 \%$, Asian; $1.5 \%$, other; and 4\%, two or more. Two of the larger cities are home to refugee populations as well as a larger population of Somalis and people of Hispanic origin. Students in the first professional year are placed in community pharmacies throughout this region. Each student is assigned to an independently owned pharmacy and a corporately owned pharmacy for one semester. Because of this, the students are exposed to diverse populations and to rural and urban settings.

The first cohort of student pharmacists included in this study were those who completed the four professional (P1-P4) years of the Doctor of Pharmacy (PharmD) program from August 2012 to May 2016 (hereafter referred to as cohort 2016, based on their graduating year). Students' understanding of health literacy, application of health literacy-related skills, and cultural competency was assessed six times: at the beginning of the professional program, after completion of the first semester, and at the end of each academic year (Figure 1). Health literacy and cultural competency concepts were introduced in the fall semester of the P1year as previously described. ${ }^{18}$ In brief, three courses were chosen in which to integrate concepts. These three courses provided time for students to participate in active-learning exercises that allowed them to apply the health literacy and cultural competency concepts they had learned. In the spring semester of the P1 year, students did not receive any reinforcement of the concepts they had learned the previous fall because the curriculum focused on pharmaceutical science concepts. Students has an initial increase in health literacy and cultural competency concepts from baseline to the end of the fall semester, which declined by the end of the academic year. While the declines still resulted in higher scores than baseline, the initial increases were not sustained.

As noted above, findings from this initial study in 2012 were previously published and served as the foundation for this study. ${ }^{18}$ Assessment of students was extended beyond the P1 year to examine the entire curriculum in order to determine appropriate interventions. To address 


\section{A. Initial Integration Across the Curriculum}

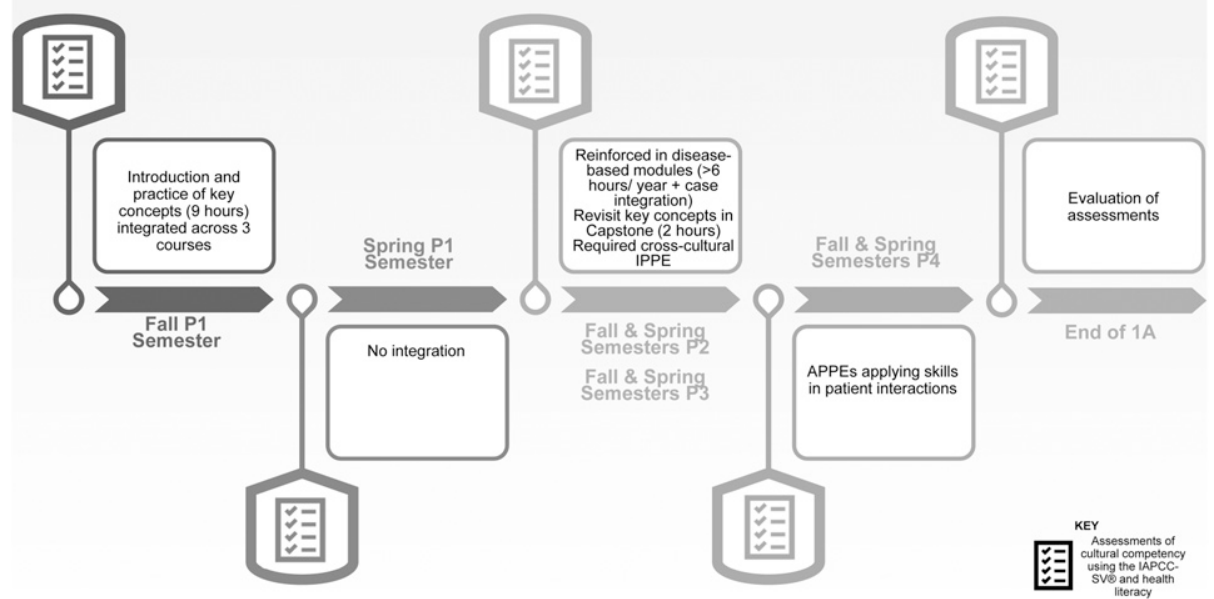

\section{B. Focused Integration in the Spring P1 Semester}

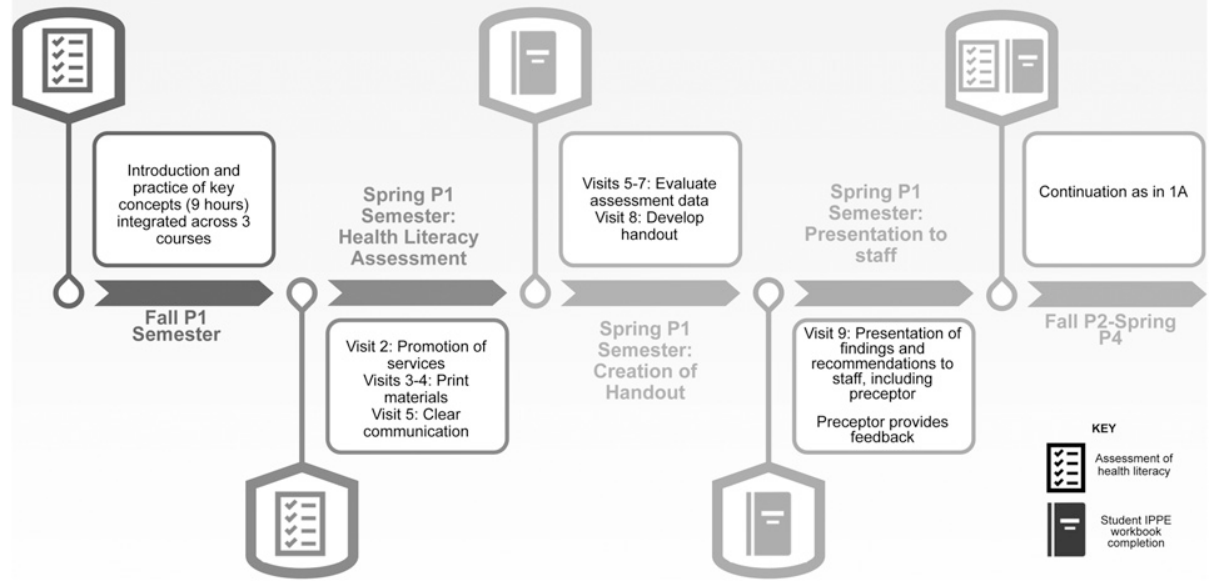

Figure 1. Integration of Health Literacy and Cultural Competency Content and Assessments Throughout the Curriculum

the shortcomings of the health literacy and cultural competency interventions made in the first study, several additional changes to the curriculum were made as described below.

As students were engaged in module-based coursework from the fall semester of the P2 year to the fall semester of the $\mathrm{P} 3$ year, we made the decision to reinforce health literacy and cultural competency concepts across these modules. For example, in the Endocrine module, students participated in active-learning activities with diabetes-specific health literacy assessments and were given an opportunity to practice counseling. In the Special Populations module, students learned and applied concepts related to the social determinants of health and health disparities.

During the spring semester of the $\mathrm{P} 3$ year, a two-hour session was added to the capstone course to bring all of the health literacy and cultural competency concepts taught in the previous years together in preparation for students beginning advanced pharmacy practice experiences (APPEs). Active-learning exercises that addressed and integrated health literacy were included during this session. Patient cases used in the capstone course for students' SOAP (subjective, objective, assessment, and plan) notes also included culture-related components. Additionally, students participated in a cross-cultural service-learning experience during the $\mathrm{P} 3$ year as a part of their introductory pharmacy practice experience (IPPE). During their P4 years, all of the skill sets that students learned in the P1 through P3 years of the curriculum were reinforced as they engaged with patients of all health literacy levels and from various cultural backgrounds during APPEs in their P4 years.

To identify improvements in students' health literacy, an assessment was created from a review of the literature and underwent faculty and student review. Students and faculty members with research and survey experience reviewed the instrument for face and content 


\section{American Journal of Pharmaceutical Education 2020; 84 (10) Article 7764.}

validity and identified any items that were unclear. The instrument was revised, and in this study, the final assessment instrument had good internal consistency when used with student pharmacists $(\alpha=0.81)$. The instrument included 23 Likert-type items (rated on a scale ranging from $1=$ strongly disagree to $7=$ strongly agree) that related to student perceptions (six items), understanding (nine items), and application (eight items) of health literacy concepts. ${ }^{18}$ Some items were worded for reverse-coding during scoring. No further validation was conducted on this instrument. A copy of the items for the health literacy instrument can be found in Appendix 1.

To assess cultural competency, a validated measure was used: The Inventory for Assessing the Process of Cultural Competence Among Health Care ProfessionalsStudent Version (IAPCC-SV, Campinha-Bacote, 2007). ${ }^{26}$ Validation efforts have found that the instrument had acceptable internal consistency $(\alpha=0.78)$ when assessed in nursing students. ${ }^{27}$ (Estimates of acceptable internal consistency values range from 0.70 and above.) ${ }^{28}$ There are no data available regarding its validity for use in pharmacy students. It contains 20 four-point Likert-type questions rated on a scale from $1=$ strongly disagree to $4=$ strongly agree across five subscales (cultural awareness, knowledge, skill, encounters, and desire) and categorizes students based on a summed score as culturally incompetent, culturally aware, culturally competent, and culturally proficient. ${ }^{26,27}$ Demographic information also was obtained from students, and on the post-assessment, students were asked to relate whether they planned to use the information in the future.

One of the issues identified through assessment of the longitudinal data was that students had initial improvement in health literacy and cultural competency during the fall P1 semester when these concepts were introduced, but in the spring semester of the P1 year, when there were no focused reinforcement of concepts, declines were seen. ${ }^{18}$ To address these issues, faculty members worked with the experiential team to integrate a patientcentered, longitudinal activity in health literacy during the P1 spring semester. Students completed 10, five-hour IPPE visits at an independent or chain community pharmacy practice site. As part of the IPPE, students completed weekly workbook activities at their practice site to reinforce different health literacy concepts. The Agency for Healthcare Research and Quality (AHRQ) designed a health literacy assessment tool for pharmacists to examine how well a pharmacy is addressing the needs of patients with limited health literacy from the perspectives of an objective auditor, pharmacy staff members, and patients. $^{29}$ This tool is available to pharmacies to help identify areas in need of improvement in order to increase the health literacy accessibility of their pharmacy for their patients. The "pharmacy assessment by an objective auditor" section of the AHRQ Pharmacy Health Literacy Tool was adapted and incorporated into the workbook and separated into weekly activities to assess how well the pharmacy was prepared to care for patients with low health literacy. ${ }^{29}$ During the first few weeks, students assessed the pharmacy on the incorporation of health literacy principles in written patient education materials, promotional service materials, and verbal communication. On each item, the student rated the pharmacy by selecting one of the following statements: this is something the pharmacy does not appear to be doing; the pharmacy is doing this but could make improvements; or the pharmacy is doing this well. ${ }^{29}$ Students then spent two weeks evaluating their assessment in order to identify strengths and areas of improvement for the pharmacy. They searched the literature for evidence-based health literacy recommendation and created a handout to present their findings to pharmacy staff members. Finally, the students' preceptors completed a survey addressing their perceptions of the activity (four items rated using a sevenpoint, Likert type scale ranging from $1=$ strongly disagree to $7=$ strongly agree, two open-ended items).

To assess changes in health literacy skills, another section was added to the assessment used in part one to assess students' confidence in different health literacy skills related to the activity. These skills included identifying patients with low health literacy, judging the appropriateness and readability of written health information, assessing the effectiveness of a pharmacy in catering to patients with low health literacy, judging the health literacy level of verbal communication of pharmacy staff members, and judging the physical environment of a pharmacy in regards to patients with limited health literacy. These items were rated on a five-point Likert-type scale ranging from $1=$ not at all confident to $5=$ extremely confident . One cohort (students who completed their P1 year in 2015-2016, hereafter referred to as "cohort 2019" [their graduation year]) was used as a comparator/control group and received no intervention. Two subsequent cohorts (students who completed their P1 year in 2016-2017 or 2017-2018, and hereafter referred to as cohorts 2020 and 2021 [their graduation years]) received the intervention.

In 2017-2018, following the intervention, preceptors were asked four questions (seven-point Likert-type scale, ranging from $1=$ strongly disagree to $7=$ strongly agree) regarding whether they will use the results to make changes to service promotions, written communication, and verbal communication within their pharmacy, and whether the students' presentation was helpful. The preceptors' survey also had two open-ended questions 


\section{American Journal of Pharmaceutical Education 2020; 84 (10) Article 7764.}

regarding their thoughts on the activity. The survey was included in the student IPPE workbook for preceptors to complete, and preceptor feedback was only asked in the first intervention year to minimize preceptor workload.

All data were entered into Excel, and analyses were performed using SPSS (IBM, Armonk, NY). A priori level of $\alpha=.05$ was used for determining statistical significance. Demographic information was analyzed using descriptive statistics. The data did not pass the ShapiroWilk test for normality; therefore, nonparametric tests were used. Wilcoxon signed-rank tests were used to examine differences on the health literacy assessment and the IAPCC-SV between the beginning of the P1 year and the end of the $\mathrm{P} 4$ year, midway through the $\mathrm{P} 1$ year and the end of the P4 year, and midway through the P1 year and the end of the P1 year. Any negatively worded items were reverse-coded appropriately to determine whether students' agreement regarding perceptions, understanding, and application improved or declined. Friedman tests were used to evaluate all surveys for changes over time (initial longitudinal assessment and focused P1 intervention). Mann-Whitney $U$ tests were used to compare the P1 students who received the intervention and those who did not receive the intervention. The qualitative data were analyzed using grounded theory, and more specifically, the constant comparison method. ${ }^{30}$ Two authors performed the analyses, and one author was available if consensus was not achieved. They initially performed the review individually, comparing between the data and their generated themes. They then met together to collaboratively agree upon a common set of themes. During this final phase of qualitative analysis, they continued to compare to the data.

\section{RESULTS}

Among the four cohorts, 189 students $(100 \%$ response rate) participated. Demographic information for participants is displayed in Table 1. Most students agreed or strongly agreed that they plan on continuing to use the health literacy and cultural competency skills they had learned (Table 1).

The changes between the beginning and end of the $\mathrm{P} 1$ year for cohort 2016 have been presented elsewhere for health literacy and cultural competency, with limited improvements seen between the middle and end of the P1 year. ${ }^{18}$ Specific to health literacy, the following items demonstrated significant improvement $(p<.05)$ between the middle of the P1 year and end of the P4 year: one out of six health literacy perception items (outcomes of low health literacy); four out of nine health literacy understanding items (definition of health literacy outcomes of low health literacy, the problem of health literacy in health care, and the utility of health literacy education in IPPEs); and two out of eight health literacy application items (using the teach-back method and using health literacy education in IPPEs). The significant changes seen were small, with less than a one-point change. Across all assessments, five out of six perceptions items (except for the outcomes of low health literacy) significantly improved $(p<.05)$. Further, all nine understanding items and all eight application items improved significantly $(p<.05)$. Changes were small and typically varied from a 0.5-1.5 point change, with some notable exceptions such as the ability to use the teach-back method (P1 mean $=3.6$; P4 mean $=6.5)$, how to help a patient with low health literacy $(\mathrm{P} 1$ mean $=4.0 ; \mathrm{P} 4$ mean $=6.0)$, how to create a pill card $(\mathrm{P} 1$ mean $=2.9 ; \mathrm{P} 4$ mean=6.4). With regard to cultural competency as assessed by the IAPCC-SV, students' cultural awareness, knowledge, skill, desire, and total scores significantly increased longitudinally $(p<.05)$. Most changes were small ( $<1.5$ points longitudinally), except for cultural knowledge, which had a greater increase $(\mathrm{P} 1$ mean $=12.2 ; \mathrm{P} 4$ mean=15.2). The cultural encounter domain increased but not significantly $(p=.11)$. There also were more students who achieved higher cultural competency levels than baseline (Table 2).

Table 1. Demographics of Student Pharmacists Who Completed a Doctor of Pharmacy Program in Which Health Literacy and Cultural Competency Concepts Were Integrated Throughout the Curriculum

\begin{tabular}{|c|c|c|c|c|}
\hline \multirow[b]{2}{*}{ Item } & \multicolumn{4}{|c|}{ Response, No. (\%) } \\
\hline & 2016 Cohort $(n=53)$ & 2019 Cohort $(n=41)$ & 2020 Cohort $(n=49)$ & 2021 Cohort $(n=46)$ \\
\hline \multicolumn{5}{|l|}{$\overline{\text { Gender }}$} \\
\hline Female & $32(60.4)$ & $18(43.9)$ & $31(63.3)$ & $32(69.6)$ \\
\hline \multicolumn{5}{|l|}{ Ethnicity } \\
\hline Caucasian & $47(88.7)$ & $24(58.5)$ & $37(75.5)$ & $32(69.6)$ \\
\hline Asian or Pacific Islander & $3(5.7)$ & $5(12.2)$ & $5(10.2)$ & $8(17.4)$ \\
\hline
\end{tabular}


American Journal of Pharmaceutical Education 2020; 84 (10) Article 7764.

Table 2. Initial Cohort (Cohort 2016) Cultural Competency Assessment Comparisons Across the Curriculum (IAPCC-SV)

\begin{tabular}{|c|c|c|c|c|c|c|}
\hline & $\frac{\text { Start P1 }}{\text { Mean (SD) }}$ & $\begin{array}{c}\text { Mid P1 } \\
\text { Mean (SD) } \\
\end{array}$ & $\begin{array}{c}\text { End P1 } \\
\text { Mean (SD) }\end{array}$ & $\begin{array}{c}\text { End P2 } \\
\text { Mean (SD) } \\
\end{array}$ & $\begin{array}{c}\text { End P3 } \\
\text { Mean (SD) } \\
\end{array}$ & $\begin{array}{c}\text { End P4 } \\
\text { Mean (SD) }\end{array}$ \\
\hline Item & $\mathrm{N} \%$ & $\mathbf{N \%}$ & $\mathrm{N} \%$ & $\mathbf{N \%}$ & $\mathrm{N} \%$ & $\mathrm{N \%}$ \\
\hline$\overline{\text { Cultural Awareness }^{\mathrm{a}}}$ & $9.7(1.6)$ & $10.7(1.0)$ & $10.3(1.9)$ & $10.7(1.2)$ & $10.5(1.2)$ & $10.1(1.6)$ \\
\hline Cultural Knowledge $^{\mathrm{a}}$ & $12.2(2.3)$ & $14.7(2.3)$ & $14.8(3.1)$ & $15.1(2.5)$ & $15.3(2.3)$ & $15.2(2.0)$ \\
\hline Cultural Skill $^{\mathrm{a}}$ & $7.4(1.7)$ & $9.3(1.5)$ & $8.4(2.2)$ & $9.1(1.5)$ & $8.8(1.5)$ & $8.7(1.8)$ \\
\hline Cultural Encounter $^{\mathrm{a}}$ & $15.3(2.3)$ & $16.1(1.8)$ & $15.0(3.6)$ & $15.5(2.1)$ & $15.7(1.8)$ & $15.5(2.3)$ \\
\hline Cultural Desire $^{\mathrm{a}}$ & $13.5(2.1)$ & $14.6(1.6)$ & $13.8(3.0)$ & $13.7(1.8)$ & $13.8(1.8)$ & $13.6(2.0)$ \\
\hline Total IAPCC-SV Score ${ }^{b}$ & $58.0(7.9)$ & $65.4(6.1)$ & $62.2(11.8)$ & $64.1(7.3)$ & $64.1(6.8)$ & $63.3(7.6)$ \\
\hline Competence Level $^{\mathrm{c}}$ & $2.4(0.6)$ & $3.0(0.5)$ & $2.8(0.6)$ & $2.8(0.6)$ & $2.8(0.6)$ & $2.7(0.6)$ \\
\hline Culturally Incompetent (20-40) & $2(3.5)$ & $0(0.0)$ & $1(1.8)$ & $0(0.0)$ & $0(0.0)$ & $1(1.8)$ \\
\hline Culturally Aware (41-59) & $28(49.1)$ & $7(12.3)$ & $13(22.8)$ & $17(29.8)$ & $13(22.8)$ & $14(24.6)$ \\
\hline Culturally Competent (60-74) & $22(38.6)$ & $41(71.9)$ & $33(57.9)$ & $30(52.6)$ & $27(47.4)$ & $27(47.4)$ \\
\hline Culturally Proficient (75-80) & $1(1.8)$ & $5(8.8)$ & $5(8.8)$ & $5(8.8)$ & $5(8.8)$ & $3(5.3)$ \\
\hline
\end{tabular}

${ }^{\mathrm{a}}$ Scores for the five cultural constructs are determined by the IAPCC-SV (Campinha-Bacote, 2007)

${ }^{\mathrm{b}}$ Total IAPCC-SV score is summed from the five cultural constructs

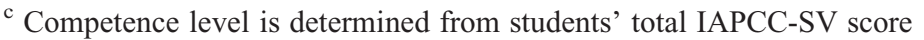

The items for the survey questions described can be found in Appendix 1. For the other cohorts participating in the health literacy intervention portion of the study, there were no significant differences between the no intervention (cohort 2019) and intervention (cohorts 2020, 2021) posttest values on application or confidence items and all but one perception item. Those who completed the intervention in their IPPE agreed significantly more with the utility of learning about the issue of health literacy and how to address it within their IPPE than did the cohort without the intervention $(\mathrm{P} 1$ mean $=4.7 ; \mathrm{P} 4$ mean $=5.5$; $p=.03$ ).

For the group without an intervention (cohort 2019), there were significant increases $(p<.05)$ through the three assessments in the P1 year: three out of six perception items (items 1-3), seven out of nine understanding items (items 1-2, 4-8), five out of eight application items (items $1-3,5,8$ ), and five out of six confidence items (items 2-6). Between end of the fall P1 semester to the end of theP1 academic year, there were significant increases on one perception item (item 6), one understanding item (item 5), and two application items (items 3,5). These increases were mainly small in nature, typically with less than a one-point change.

For the first intervention group (cohort 2020), there were significant increases $(p<.05)$ through the three assessments in the P1 year: four out of six perception items (items 2-5), all nine understanding items, six out of eight application items (items 1-3, 5-6, 8), and all six confidence items. Between mid-P1 and end-P1, students' scores on one perception item (item 6) increased significantly, as did scores on four understanding items (items
$1-2,4,6$ ), and three confidence items (items 4-6). For the first intervention group (cohort 2020), there were significant increases $(p<.05)$ through the three assessments in the P1 year: three out of six perceptions items (items 1-2, 6), all nine understanding items, all eight application items, and all six confidence items. Between mid-P1 to end-P1, students' scores increased significantly on one perception item (item 6) and one confidence item (item 3). These increases were mainly small in nature, typically resulting in less than a one-point change.

\section{Preceptor Perceptions}

As a part of the IPPE health literacy intervention, 44 preceptors assessed the activity (90\% response rate). Preceptors agreed that they would use the results of the health literacy assessment performed by the students to make changes in promotional materials (median $=6$, $\mathrm{IQR}=5-7$ ), print materials (median $=6, \mathrm{IQR}=4-7$ ), and verbal communications (median $=6, \mathrm{IQR}=6-7$ ). Preceptors also agreed that it was helpful to have students educate the pharmacy staff on the importance of health literacy (median=6.5, IQR=6-7).

When analyzing the preceptors' comments, three main themes emerged that were common among the participating pharmacies: difficult to implement findings due to corporate regulations, an outside perspective was helpful, and the assessment overall was helpful. Other less common statements included the time challenges to implement the suggested changes as well as how the changes would improve patient trust in the pharmacy. Preceptor felt they could address the corporate regulation barrier by attempting to discuss further with management. 


\section{American Journal of Pharmaceutical Education 2020; 84 (10) Article 7764.}

Preceptors appreciated the time the students put into their presentations. Examples of preceptor responses in each of these categories are provided in Appendix 2.

\section{DISCUSSION}

The integration of cultural competency and health literacy concepts throughout the curriculum initially increased student pharmacists' cultural competency and perceptions, understanding, and application of health literacy. However, the increase seen for cohort 2016 during the fall semester of their P1 year was not sustained when the students were tested again in the spring P1 semester, during which there was no integration of these concepts. Adding health literacy content in the spring P1 year by having students apply concepts during IPPEs improved the health literacy skills of student pharmacists in cohorts 2020 and 2021. Continual revision and improvement of curricula is important for students to develop in their application of the Pharmacists' Patient Care Process as well as to enhance their skills and preparedness to work with diverse populations. ${ }^{10,12}$

The integration of cultural competency content and assessments throughout the curriculum resulted in significant improvements for six out of seven items in addition to improvements in the IAPCC-SV score and competence level in the first semester. Cultural awareness, knowledge, skill, and total IAPCC-SV scores increased from culturally aware to culturally competent after the introduction and practice of key concepts in the fall of the P1 semester. Changes in the students' cultural encounters item were not significantly improved in the first semester or at the end of the study. A 10-week cultural competency elective course at the Massachusetts College of Pharmacy and Health Sciences introduced students to cultural competency concepts within the profession of pharmacy. The students were introduced to multiple cultural groups through local liaisons, conducted health care screenings at community centers, and reviewed cultural groups in presentations. The students showed similar improvements in the first four domains but not in cultural skills as measured by the IAPCC-SV.$^{31}$ Multiple interventions were made throughout the second year of pharmacy school at the University of Toledo, including lectures, videos regarding cultural competency in pharmacy followed by discussions, laboratory activities, and a cross-cultural experience with a diverse group of people. These activities also resulted in a significant increase in students' knowledge of and confidence in cultural competency, especially in areas of patient counseling $(p<.01)$ as assessed by a questionnaire they developed. ${ }^{32}$ Vyas and Claiguiri implemented a cultural competency series at the University of Missouri-Kansas
City School of Pharmacy at the Columbia satellite campus that had less heterogeneity in terms of cultural groups. The six-week series, which was integrated into an IPPE, included an introductory lecture, patient care scenarios, and sessions on religion, socioeconomic factors, and health disparities. Students' perceptions and understanding of cultural competency were increased according to an unvalidated 18 -item survey instrument. ${ }^{33}$ Additionally, the incorporation of patient empathy modeling into a Purdue University underserved ambulatory care APPE intended to increase student's understanding of and empathy towards underserved populations allowed students to simultaneously learn and apply the concepts. Students simulated the life of a patient with barriers to health care, encountered different scenarios that they had to navigate, completed activities related to community resources, and discussed their thoughts and perceptions in debriefing scenarios. ${ }^{34}$

While most of these institutions are located within a larger metropolitan area, our access to large metropolitan areas provided similar opportunities for external encounters. Compared to these studies, the integration into Cedarville's curriculum was longer and throughout many courses/modules (across all years vs an elective or one academic year). However, the incorporation into IPPEs and APPEs was less intentional. A cross-cultural servicelearning experience is required, but students can choose which patient group(s) they encounter. Further, there is less guided reflection in APPEs related to encountering different cultural groups. The differences between significant items could relate to the number of cultural competency interventions and the time between interventions and assessment of cultural competency. Perhaps the activities integrated throughout the curriculum were not sufficient to improve students' perceived ability to interact and engage with other cultural groups. More intentional simulations and experiences with cultural groups may be beneficial. However, all the improvements in cultural competency indicate that incorporation of concepts across the curriculum may have a sustained impact on learning for all students.

The introduction of health literacy and cultural competency concepts in the fall of the P1 year and then continued reinforcement in the $\mathrm{P} 2$ year, reiteration in the capstone course and cross-cultural IPPEs, and application of health literacy in APPEs all played a part in cementing health literacy aspects for student pharmacists. Shorter integrations of health literacy concepts have been successful in improving student pharmacists' knowledge, confidence, and attitudes. For example, the effectiveness of a three-hour multifaceted module on health literacy at the University of California San Diego Skaggs School of Pharmacy was assessed with an unvalidated pre- and 


\section{American Journal of Pharmaceutical Education 2020; 84 (10) Article 7764.}

post-assessment of health literacy confidence. Students participated in a one-hour lecture and two-hour workshop that included videos, health literacy assessment tools, and team activities. Researchers found significant improvements in six of seven areas assessed $(p<.001) .{ }^{35}$ At the University of the Incarnate Word Feik School of Pharmacy, a case-based learning intervention focused on health literacy within a laboratory course. Students were able to learn about the basics of health literacy, risk factors, recognizing patients with limited health literacy, and how to address health literacy as part of the laboratory pre-readings and during the two-hour case discussion. Third-year pharmacy students' health literacy knowledge was significantly improved $(10$-item quiz, $p<.001){ }^{36}$ Meanwhile, health literacy concepts were addressed in a one-hour class session and a three-hour skills laboratory in a first professional year patient-centered communications course at the University of Colorado Skaggs School of Pharmacy. Students also participated in coordinating IPPE activities. This intervention improved the following facets of health literacy: knowledge, abilities, confidence, perceptions, and understanding. These students were found to meet or exceed expectations of their objective structured clinical examination grading rubrics. In addition, following the intervention, the students had higher perceived confidence and attitudes than thirdyear professional students who had not completed the course. $^{37}$

The intervention by Skaggs School of Pharmacy was closest to our intervention model, given that the course content also aligned with IPPE activities. Scores on items declined between the end of the fall semester of the P1 year and beginning of the spring semester of the P1 year for students in the initial longitudinal analysis of our study. A health literacy activity was added to first-year students' spring IPPE to address this. Not only were activities introduced and reinforced in both courses and laboratories, but further integrations occurred throughout the curriculum and during P1 IPPEs in later cohorts. This reinforces that the integration of such concepts is beneficial to improve student knowledge, confidence, and attitudes, especially when integrating it alongside opportunities to practice the skills they learned. Further, active learning was used, which concurs with these interventions where activities such as patient health literacy assessment, altering the health literacy level of a document, and patient counseling improved students' health literacy perceptions, understanding, and confidence. ${ }^{35-37}$

Preceptor modeling, experiences with patients, and a lack of focus on these concepts all could contribute to the score decreases seen. Preceptors play a critical role in helping student pharmacists apply knowledge, attitudes, skills, and values taught in the didactic curriculum. Yet, if they themselves do not consider it important, it can negatively impact student application. Less than $50 \%$ of preceptors surveyed by Bond and colleagues felt health literacy and cultural competency skills were "very important." 38 Preceptor "buy-in" and professional development in the area of health literacy and cultural competency skills are needed for integration of health literacy and cultural competency in IPPEs and APPEs to be successful. When preceptors are engaged and these concepts are incorporated, students can gain valuable experience. Preceptors responded positively to our intervention, and it provided an opportunity for students to share information they had learned with their preceptors. While preceptors had some concerns about how to implement suggested changes because of company policies, they found the outside perspective regarding their pharmacy health literacy-appropriate practices helpful. This intervention required minimal preceptor time and incorporated students, which may have contributed to its success. Similarly, a case study of eight community pharmacies representing a variety of geographic areas and populations using the AHRQ survey identified barriers, including minimal leadership buy-in and inadequate time, while the presence of students and residents and a culture of innovation increased the use of the AHRQ survey and improvements in health literacy. ${ }^{39}$

There are several limitations to this study, including a single institution implementation, a non-validated health literacy assessment, and a small sample size. Thus, the findings may not be applicable to other institutions, particularly those with larger student cohorts and/or are not private. Additionally, the use of survey instruments could introduce social desirability bias. For example, students may perceive that there are certain responses that are desirable to society; thus, they may minimize undesirable answers and maximize desirable ones rather than answer honestly. ${ }^{40}$ Other quantitative assessments, such as patient simulations, would be important to assess students' skills. Further research should be done to create and implement a validated instrument to assess the health literacy skills of pharmacy students.

\section{CONCLUSION}

After conducting a longitudinal study of students' perceptions and knowledge of cultural competency and health literacy, students' health literacy perceptions, application, and understanding increased as did their cultural competency. Through an intervention, students' health literacy perceptions, application, understanding, and confidence increased. However, students in the control groups experienced similar increases on many of the 


\section{American Journal of Pharmaceutical Education 2020; 84 (10) Article 7764.}

items, suggesting that these increases may not have been directly attributable to the intervention. Students and preceptors did find the IPPE intervention beneficial and thought that it should continue in order to further increase understanding of health literacy. Thus, systematically addressing cultural competency and health literacy concepts and identifying areas for improvement may be beneficial to improve pharmacy students' outcomes and ability to work with all patient populations.

\section{ACKNOWLEDGMENTS}

This project was supported by an internal grant from Cedarville University School of Pharmacy. Thank you to Dr. Josepha Campinha-Bacote for permission to use the IAPCC-SV (Campinha-Bacote, 2007).

\section{REFERENCES}

1. Institute of Education Sciences: National Center for Education Statistics. Program for the International Assessment of Adult Competencies (PIAAC): PIACC 2012/2014 results. 2014; https:// nces.ed.gov/surveys/piaac/results/summary.aspx. Accessed September 21, 2020.

2. Institute of Medicine. Health literacy: A prescription to end confusion. National Academy of Sciences; 2004.

3. U.S. National Library of Medicine: National Network of Libraries of Medicine. Health literacy. https://nnlm.gov/initiatives/topics/ health-literacy. Accessed September 21, 2020.

4. Lor M, Koleck TA, Bakken S, Yoon S, Dunn Navarra A-M. Association between health literacy and medication adherence among hispanics with hypertension. J Racial Ethn Health Disparities. 2019;6(3):517-524.

5. National Institutes of Health Office of Communications \& Public Liaison. Clear Communication. https:/www.nih.gov/institutes-nih/ nih-office-director/office-communications-public-liaison/clearcommunication. Accessed September 21, 2020.

6. O'Connell MB, Korner EJ, Rickles NM, Sias J. Cultural competence in health care and its implications for pharmacy part 1 : Overview of key concepts in multicultural health care.

Pharmacotherapy. 2007;27(7):1062-1079.

7. O'Connell MB, Rickles NM, Sias J, Korner EJ. Cultural competency in health care and its implications for pharmacy part 2: Emphasis on pharmacy systems and practice. Pharmacotherapy. 2009;29(2):14e-34e.

8. O'Connell MB, Rodriguez de Bittner M, Poirier TI, et al. Cultural competency in health care and its implications for pharmacy part 3A: Emphasis on pharmacy education, curriculums, and future directions. Pharmacotherapy. 2013;33(12):347-367.

9. Medina MS, Plaza CM, Stowe CD, Robinson ET, DeLander G, et al. Center for the Advancement of Pharmacy Education 2013 educational outcomes. Am J Pharm Educ 2013;77(8):Article 162. 10. Accreditation Council for Pharmacy Education. Accreditation standards and key elements for the professional program in pharmacy leading to the doctor of pharmacy degree: Standards 2016. 2015; https://www.acpe-accredit.org/pdf/Standards2016FINAL.pdf. Accessed September 21, 2020.

11. O'Connell MB, Jackson AN, Karaoui LR, et al. Cultural competency in health care and its implications for pharmacy part 3B:
Emphasis on pharmacy education policy, procedures, and climate. Pharmacotherapy. 2013;33(12):368-381.

12. Joint Commission of Pharmacy Practitioners. Pharmacists' Patient Care Process. 2014. https://www.pharmacist.com/sites/ default/files/files/PatientCareProcess.pdf. Accessed September 21, 2020.

13. Wenger LM, Rosenthal M, Sharpe JP, Waite N. Confronting inequities: a scoping review of the literature on pharmacist practice and health-related disparities. Res Social Adm Pharm.

2016;12(2):175-217.

14. Capehart KD. Development and implementation of a health literacy elective in a pharmacy curriculum. Am J Pharm Educ. 2008;72(3):Article 72.

15. Devraj R, Butler LM, Gupchup GV, Poirier TI. Active-learning strategies to develop health literacy knowledge and skills. Am J Pharm Educ. 2010;74(8):Article 137.

16. Poirier TI, Butler LM, Devraj R, Gupchup GV, Santanello C, Lynch JC. A cultural competency course for pharmacy students. Am J Pharm Educ. 2009;73(5):Article 81.

17. Sicat BL, Hill LH. Enhancing student knowledge about the prevalence and consequences of low health literacy. Am J Pharm Educ. 2005;69(4):Article 62.

18. Cailor SM, Chen AMH. Immediate and longitudinal effects of incorporating health literacy and cultural competency into a yearlong pharmacy curriculum. Curr Pharm Teach Learn. 2015;7(3):292-301. 19. Aspden T, Sheridan J, Harrison J. "Talking and thinking": Impact of a simulation on pharmacy undergraduates' beliefs and attitudes about living in poverty. Curr Pharm Teach Learn. 2016;8(4):447-457. 20. Arif SA, Cryder BT, Mazan J, Quinones-Boex A, Cyganska A. Using patient case video vignettes to improve students' understanding of cross-cultural communication. Am J Pharm Educ. 2017;81(3):Article 56.

21. Haack S. Engaging pharmacy students with diverse patient populations to improve cultural competence. Am J Pharm Educ. 2008;72(5):Article 124.

22. Haack S, Phillips CD. Teaching cultural competency through a pharmacy skills and applications course series. Am J Pharm Educ. 2012;76(2):Article 27.

23. Cooper L-A, Vellurattil RP, Quinones-Boex A. Pharmacy students' perceptions of cultural competence encounters during practice experiences. Am J Pharm Educ. 2014;78(2):Article 31. 24. Wilby KJ, Taylor J, SKhalifa SI, Jorgenson D. A course-based cross-cultural interaction among pharmacy students in Qatar and Canada. Am J Pharm Educ. 2015;79(2):Article 26.

25. Sales I, Jonkman L, Conor h, Hall D. A comparison of educational interventions to enhance cultural competency in pharmacy students. Am J Pharm Educ. 2013;77(4):Article 76. 26. Campinha-Bacote J. Inventory for Assessing the Process of Cultural Competence-Student Version. http://transculturalcare.net/ iapcc-sv/. Accessed September 21, 2020.

27. Fitzgerald EM, Cronin SN, Campinha-Bacote J. Psychometric testing of the Inventory for Assessing the Process of Cultural Competence among healthcare professionals-Student Version (IAPCC-SV). J Theory Constr Test. 2009;13(2):64-68.

28. Tavakol M, Dennick R. Making sense of Cronbach's alpha. Int $J$ Med Educ. 2011;2:53-55.

29. AHRQ health literacy tools for use in pharmacies. 2013; http:// www.ahrq.gov/professionals/quality-patient-safety/pharmhealthlit/ tools.html. Accessed September 21, 2020. 


\section{American Journal of Pharmaceutical Education 2020; 84 (10) Article 7764.}

30. Kolb SM. Grounded theory and the constant comparative method: Valid research strategies for educators. Journal of Emerging Trends in Educational Research and Policy Studies. 2012;3(1):83-86. 31. Durand C, Abel C, Silva M, Desilets A. An elective course in cultural competence. Curr Pharm Teach Learn. 2012;4(2):102-108. 32. Muzumdar JM, Holiday-Goodman M, Black C, Powers M. Cultural competence knowledge and confidence after classroom activities. Am J Pharm Educ. 2010;74(8):Article 50.

33. Vyas D, Caligiuri F. Reinforcing cultural competency concepts during introductory pharmacy practice experiences. Am J Pharm Educ. 2010;74(7):Article 129.

34. Chen JT, LaLopa J, Dang DK. Impact of patient empathy modeling on pharmacy students caring for the underserved. Am J Pharm Educ. 2008;72(2):Article 40.

35. Mnatzaganian C, Fricovsky E, Best BM, Singh RF. An interactive, multifaceted approach to enhancing pharmacy students' health literacy knowledge and confidence. Am J Pharm Educ. 2017;81(2):Article 32.

36. Ha H, Lopez T. Developing health literacy knowledge and skills through case-based learning. Am J Pharm Educ. 2014;78(1):Article 17. 37. Trujillo JM, Figler T. Teaching and learning health literacy in a

Doctor of Pharmacy program. Am J Pharm Educ. 2015;79(2): Article 27. 38. Bond R, Godwin D, Thompson ME, Wittstrom K. Preceptor perceptions of the importance of experiential guidelines. Am J Pharm Educ. 2013;77(7):Article 144.

39. Shoemaker SJ, Staub-DeLong L, Wasserman M, Spranca M. Factors affecting adoption and implementation of AHRQ health literacy assessment tools in pharmacies. Res Social Adm Pharm. 2013;9(5):553-563.

40. Nederhof AJ. Methods of coping with social desirability bias: A review. Eur J Soc Psychol. 1985;15(3):263-280. 
American Journal of Pharmaceutical Education 2020; 84 (10) Article 7764.

Appendix 1. Health Literacy Intervention Survey Items

\begin{tabular}{|c|c|}
\hline Category & Items \\
\hline Perceptions $^{\mathrm{a}}$ & $\begin{array}{l}\text { 1. A majority of U.S. adults have difficulty using print materials to accomplish everyday tasks. } \\
\text { 2. People commonly hide their difficulty with reading or understanding. } \\
\text { 3. The teach-back method is useful in communicating with patients. } \\
\text { 4. Low health literacy can lead to poorer health outcomes. } \\
\text { 5. Patients remember most of what healthcare professionals tell them. } \\
\text { 6. Most health information is written at patients' reading level. }\end{array}$ \\
\hline Confidence $^{c}$ & $\begin{array}{l}\text { 1. I can identify patients with low health literacy. } \\
\text { 2. I can judge the appropriateness of written health information for patients with low health literacy. } \\
\text { 3. I can reduce the readability of written health information to a } 5 \text { th grade level. } \\
\text { 4. I can assess the effectiveness of a pharmacy in catering to patients with low health literacy. } \\
\text { 5. I can judge if a pharmacy staff uses clear verbal communication when talking with a patient with } \\
\text { low health literacy. } \\
\text { 6. I can judge if the physical environment of a pharmacy (eg, pharmacy signs, bulletin board, } \\
\text { promotional material) is user-friendly for patients with limited health literacy. }\end{array}$ \\
\hline
\end{tabular}

a 7-point Likert-type scale, $1=$ Strongly Disagree, $7=$ Strongly Agree

b 5 -point Likert-type scale, $1=$ Never, $5=$ Always

${ }^{c} 5$-point Likert-type scale, $1=$ Not at all confident, $5=$ Extremely confident

Appendix 2. Preceptor Comments Provided in Response to the Integration of Health Literacy Concepts in the Experiential Curriculum

\begin{tabular}{ll}
\hline Theme $^{\text {a }}$ & \multicolumn{1}{c}{ Representative Quotes } \\
\hline Implementation & "We have tried those things and corporate wasn't on board, but it's a good time to revisit." \\
"We have tried this and corporate did not like it, but it is a good time to try again." & "Nice to have a fresh set of eyes looking at our pharmacy." \\
Outsider's View & "It's good to look through someone else's eyes." \\
& "I really like to see perceptions from someone not within the XX organization I helps me to see \\
"Vhat my patients may be seeing." & "Very helpful information" \\
Assessment was Helpful & "The assessment is good and valid." \\
&
\end{tabular}

${ }^{a}$ As determined by qualitative analysis 